\title{
Locus of Control and Teacher Student Interaction of the Adolescent Students within the Prison of Shyness
}

\author{
Srijan Sengupta ${ }^{1}$, Sangeeta Banerjee ${ }^{2}$, Prof. Anjali Ray ${ }^{3}$
}

\section{ABSTRACT}

Background: Puberty is the time of stress and storms. shyness is one of the trait which determine their future interaction and interpretation of outer world. So this study tries to focus on this trait from the point of view of Indian culture where become shy is taken as a good trait of the students.

Aims: The present study aimed at understanding the shyness of the adolescent student and how shyness makes an impact on their interaction with teachers and their locus of control.

Sample: A sample of 150 students from Bengali and English medium school was selected from the 12 different schools.

Methods: The data were collected by using 4 different tools (interview schedule, shyness scale, teacher student interaction scale and locus of control inventory) and processed by applying ANOVA and correlational analysis.

Results: Results showed: 1. Level of shyness higher in case of females than males but the medium of instruction did not show any marked significance in case of shyness 2 . Shyness had marked specificity in terms of both teacher student interaction and locus of control. 3. Shyness was positively correlated with other two factors.

Conclusion: It might be concluded that shyness is an important trait which make a qualitative difference among the students and it affect shy student's quality of life. It not only affect their academic life it also affect their interaction and relationship with others in all the domain of their life.

Keywords: Shyness, Teacher Student Interaction and Locus of Control

The late childhood and adolescent years are a time in which elevated self consciousness and preoccupation with social status are increasingly normative (Harter,1999). The onset of puberty brings an acutely new awareness of one's physical appearance, and also the ability to take both one's own perspective and the perspectives of others into account. Therefore others positive or negative evaluations become an increasingly salient component of self appraisals as children

\footnotetext{
${ }^{1}$ Research Scholar, Department of Applied Psychology, University of Calcutta

${ }^{2}$ Research Scholar, Department of Applied Psychology, University of Calcutta

${ }^{3}$ Professor, Department of Applied Psychology, University of Calcutta.

(C) 2015 I S Sengupta, S Banerjee, A Ray; licensee IJIP. This is an Open Access Research distributed under the terms of the Creative Commons Attribution License (http://creativecommons.org/licenses/by/2.0), which permits unrestricted use, distribution, and reproduction in any Medium, provided the original work is properly cited.
} 


\section{Locus of Control and Teacher Student Interaction of the Adolescent Students within the Prison of Shyness}

approach adolescence. In the current scenario students strive hard to achieve academic and social goals. With changing social and economic pattern of life, competition among the students is increased very much. It also found that shyness is the most influencing factor in this context. Shyness is a term which frequently used but often misinterpreted. It has the various meanings with regards people encounter difficulties in different social situations. For example, it refers to an individual's transitory experience, as well as to his or her stable characteristics. In this sense shyness involves cognitive, somatic and behavioral components (Crozier, 2001). Shyness as an emotional state is considered to be universal, a blond of fear and interest adoptive in evaluation. Shyness as a personality trait creates discomfort or inhibition in social situations and interferes with our suing one's interpersonal or professional goals (Henderson, et. al., 2010). Shyness also defined as the tendency to feel tense, worried or awkward during social interactions especially with unfamiliar people (Cheek, et. al., 1986). Zimbardo (1977), a pioneer in the study of shyness, argued that the condition exists as a continuum, ranging from the 'true blue', chronically shy person ( $4 \%$ of the population) through those who are shy only in some situations, to the 'shy extroverts' who seem to be outgoing and sociable but may be feeling shy underneath (20\% of the population). He suggested that shyness was a universal experience, affecting everybody to a greater or lesser extent. The cause and consequences of Shyness has multiple dimensions in student's life. However, except for possible genetic factors, it may be said that Shyness is the result of a process. This process can be explained in several ways, depending on the psychological current followed by the professional. Each current emphasizes a set of factors or causes (Parents-or one of them-is very aggressive, Silent or public humiliating experiences, critical relatives, shaming family problems and unaffectionate or cold families) to develop Shyness and related social problem.

Buss (1985) distinguishes between two types of shyness, namely fearful shy and Self conscious shy. Fearful shyness develops early in life and associated with high emotional reactivity leads to greater susceptibility to negative social conditioning and a tendency to display fear and a tendency to display fear and inhibition (Henderson, 2002). Self conscious shyness develops later in life and involves a tendency to be overtly aware of the public aspect of oneself as social object (Crozier, 2002).

Symptoms of shyness is act as the part of students overall personality or as a situation specific response to some particular factors. It is generally seen that students who are shyer are less responsive in their classes. Some children have not developed effective conversational skills or they do not respond positively to their verbal initiations, and they have not had much opportunity to interact with peers and their teachers. (Honig, 1987; Thompson \& Rudolph, 1992) the teacher is a central figure in any classroom learning environment especially Indian school settings where the teachers controls the teaching-learning process have with their students determines the nature of their interpersonal relationship and enables the teacher to improve their teaching practices. Today teachers and students spend a substantial amount of time interacting with one another in classroom (Gupta and Fisher, 2011). Brophy (1995) surveyed effective teachers to find out how 


\section{Locus of Control and Teacher Student Interaction of the Adolescent Students within the Prison of Shyness}

they responded to shy students. He stated that to make a healthy class environment teacher should maintain a healthy interaction with the students who are shy to make them comfortable. In a study

Roorda, Debora; ten HageThijs, Jochem; Koomen, Helman, Judith (1998) try to found out the theoretical perspective to examine the interactions between Dutch teachers and students in the schools. Interpersonal Theory provides explanations for dyadic interaction behaviours by stating that complementary behaviours (dissimilar in terms of control and similar in terms of affiliation) elicit and sustain each other. Independent observers rated teachers and children's behaviour along the interpersonal dimensions of control and affiliation. Teachers reported on children's shyness and the quality of teacher student relationship. Multilevel modeling provided correlational evidence for complementarities within and between dyads. Cross lagged analyses revealed that teachers showed complementarities for control and that children showed complementarities for affiliation. Children also reacted complementarily with respect to control but only if they were shy and shared positive relationship with their teachers.

It has been found out from the several researches that attribution of the individuals is linked with the development and perpetuation of the shyness (Bruch and Pearl, 1995). Attributions refers to the causal judgment people make use in order to explain several events which happened in their life and others life (Fosterling, 1988). Causes are interpretations that are used by the perceiver to explain the relation between an event and outcome (Weiner, 1986). In this context Rotter (1966) introduced the concept locus of control that emphasized the individual's view about causality. Individuals characterized as "internal" perceive that outcomes were attributable to skills and "external" perceived outcomes were attributable to luck or fate. Bruch and Pearl (1995) found a strong relationship among causal factors locus, stability and uncontrollability with shyness. Their finding illustrated that from the causal dimensions controllability is the strong predictor of shyness and locus also provide some specific indication of shyness. They also mentioned that controllability corroborated more in predicting shyness, whilst locus of the persons also corroborated in predicting their shyness.

According to Henderson and Zimbardo (1998) shy people tend to reverse the concept of self enhancement bias. Generally bias causes individuals tendency to praise their accomplishment and externalize their failure. This attribution style preserves their self worth and encourages the maintenance of interpersonal and occupational needs. Shy individuals on the other hand seen to reverse their bias by holding themselves responsible for their disappointments and externalizing their achievements.

In the light of the above findings, the present research aimed to investigate the relationship between shyness and teacher student interaction and also try to investigate the relationship between shyness and locus of control of the secondary school students of West Bengal. In addition to this researcher also try to investigate the nature of the teacher student interaction and locus of control on the basis of shyness. Accordingly following objectives are drawn: 


\section{Locus of Control and Teacher Student Interaction of the Adolescent Students within the Prison of Shyness}

- To study the nature of shyness among the male and female students.

- To study the nature of teacher student interaction of the students in terms of their level of shyness.

- To study the locus of control of the students in terms of their level of shyness.

- To study the interrelationship among the list of variable shyness, teacher student interaction and locus of control.

\section{METHOD}

\section{Participants:}

At first total 167 data was collected from the 12 different schools West Bengal. But 17 data was excluded because of excessive missing ( $>25 \%$ ). The sample consist 150 school students (male and female). The data collected from the different districts of West Bengal, India. Students from both medium, that is, Bengali as the first language and English as the first language, were selected. Some criteria were selected by the investigators for inclusion and exclusion of the participants in the sample group. Those criteria's were (a) Students of class ix to xi whose mother tongue Bengali, (b) Age range - 14-17 years as inclusion criteria and (c) Candidate suffering from any chronic disease (d) Students who were irregular in attendance (e) Any history of misconduct in the school as exclusion criteria.

\section{Measures:}

In the present study 4 tools are used. Firstly a Background Information Schedule was administered for collecting relevant information relating to sex, age, socio-economic status, demographic information and other mental health related issues. A measure of shyness obtained by using shyness scale, this scale was developed by Chatterjee \& Ray (2003). It was a 5-point scale rated as 1 to 5 . Here 1 indicates 'never' and 5 indicates 'always' for positive item and viceversa. The scoring rationale is that high scores indicated the greater degree of shyness and the low score indicates the lesser degree. Spilt Half Reliability Coefficient of the scale was .81.

A measure of teacher-student interaction was obtained by using Teacher-Student Interaction Scale which was developed by Gidden and Lovell (1968). Data was collected from students to measure their interaction with their teachers. It was a scale consisting 24 items with two types of response "yes" and "no". Here "yes” indicates a score of 1 and "no" indicates a score of 0, in case of positive items and vice-versa in case of negative items. Inter item correlation of this scale ranges from 0.26 to 0.64 .

Lastly, Locus of Control Inventory, developed by Rotter (1966), was used to measure locus of control of the subjects. It consist total 29-item (within which six items are filler items) in which a high score indicates external locus of control and a low score indicates internal locus of control. Individuals with a high internal locus of control believe that events result primarily from 
their own behaviour and actions. Rotter(1966) reported corrected spilt half reliabilities of .65 for males and .79 for females and Kuder-Richardson coefficients for various samples in the .69 to .76 range.

\section{Procedure:}

At first, investigators identified different schools of both medium which are situated in the three different districts of West Bengal, India. An extra credit was offered to the students for their participation. Some ethical considerations were followed before administering the questionnaires, those were (i).The participants of the study had to give their informed consent in order to take participation in the study, (ii) Participation was entirely voluntary and participants were informed of the nature of the study, (iii) Confidentiality of the data was regarded as the utmost importance. After obtaining their informed consent, a set of questionnaires were present to them. Three variables which were selected for this study which is defined below:

\section{Shyness:}

Shyness may be defined experientially as excessive self-focus characterized by negative selfevaluation that creates discomfort and/or inhibition in social situations and interferes with pursuing one's interpersonal or professional goals. The experience of shyness can occur at any or all of the following levels: cognitive (e.g., excessive negative self evaluation), affective (e.g., heightened feelings of anxiety), physiological (e.g., racing heart), and behavioral (e.g., failure to respond appropriately) and may be triggered by a wide variety of situational cues.

\section{Teacher Student Interaction:}

The teacher is considered a central figure in any classroom learning environment especially in Indian school settings, where the teacher controls the teaching-learning process and directs the activities of students on a day to day basis. Thus, the interaction which students have with their teachers determines the nature of their interpersonal relationship with others and enables the students to improve their communication and interaction processes. Today teachers and students spend a substantial amount of time interacting with one another in the classroom. (Gupta and Fisher,2011)

\section{Locus of Control:}

Locus of Control refers to a person's belief in how the events of their lives are controlled. Those with an external Locus of Control believe external factors are responsible for the outcome of events in their lives, whereas those with an internal Locus of Control believe their behavior and the outcomes in their lives are a product of their own decisions (Hair, Renaud \& Ramsay, 2007; Blanchard \& Henle, 2008).

Based on extensive literature review four hypothesis were formulated : 


\section{HYPOTHESIZES:}

Factorial design:

- Irrespective of sex, the nature of shyness of the student varies in terms of their sex and medium of teaching and interaction. (English and Bengali)

- Irrespective of sex, the nature of teacher student interaction of the students varies in terms of their level of shyness.(High and Low)

- Irrespective of sex, the nature of locus of control of the students varies in terms of their level of shyness.(High and Low)

\section{Correlational design:}

- The nature of interrelationship among the sets of variables- shyness, teacher student interaction and locus of control among the school students with high level of shyness and low level of shyness reveals dissimilarity.

To testing all this hypothesizes several statistical analysis was done by the investigators (a) Central Tendencies and dispersion for each of the variables would be computed, (b) Necessary co-relation and test of significance of ' $r$ ' and ANOVA would be used to test the relationship, as well as pattern of contribution of the different test variables.

\section{RESULTS}

\section{Primary analyses}

Descriptive statistics of variable shyness were presented in Table 1 which indicates Mean and SD values of shyness of the secondary school students of both Bengali and English medium. It was found from the table that in case of Bengali medium school students female $(\mathrm{M}=73.6)$ were more shy than the male $(\mathrm{M}=60.86)$. The homogeneity of result also found in all the components of shyness, viz, Behavioural, Cognitive, Physiological and Affective. In all those four components, female scores were higher than the scores of male. But the opposite result found out in case of English medium school students. Here scores of male in shyness was higher than the female

\section{ANOVA for shyness:}

To test the research hypothesis 1, 2x2 ANOVA was performed. The result of ANOVA was presented in table 2. It was revealed from the table that the significant difference was come due to the sex $(\mathrm{F}=6.98)$ and its interaction $(\mathrm{F}=8.94)$ with different types of medium in case of overall shyness among the secondary school students. In case of different components, Behavioural, Cognitive and Physiological, of shyness variation came mainly due to sex as well as significant 
difference came due to interaction between sex and medium. But as such no significant difference came due to medium of interaction.

\section{ANOVA for locus of control and teacher student interaction:}

To test the research hypothesis 2 and 3, a 2x2 ANOVA was performed on the basis of level of shyness and sex. The result was listed in Table 3 which indicates mean value, mean difference and $\mathrm{F}$ ratio values of two variables, that is, teacher student interaction and locus of control on the basis of sex difference and different level of shyness of the students. From the table it was found that mean difference between the male and female students in teacher student interaction due to different level of shyness and sex were 2.0213 and 1.6056 respectively. It also shown from the table that a significant difference exists between male and female students due to different level of shyness $(F=9.584)$ which was significant at 0.01 level and due to sex $(F=4.449)$ which was significant at 0.05 level. It was also found that a significant difference come due to the interaction between level of shyness and sex $(\mathrm{F}=5.563)$

In case of locus of control mean difference between male and female students due to sex and level of shyness were found to be 1.2611 and .9423 respectively. The result table also shown that a significant difference also exist between the male and female students due to sex $(\mathrm{F}=6.348)$ and different level of shyness $(\mathrm{F}=3.436)$ and both the results were significant at 0.05 level.

\section{Correlation between shyness, locus of control and teacher student interaction:}

Correlation values of this three components were shown in Table 4 which indicates the correlation value of the different components of the study. From the table it was found that shyness had a significant positive correlation with teacher student interaction $(\mathrm{r}=.194)$ which was significant at 0.05 level and also with the locus of control $(r=.325)$ which was significant at 0.01 level.

\section{DISCUSSION}

In this section an attempt will be made to explain the results found by literature and research regarding various aspects of the study. While the result will be on significant and non significant result will also be discussed.

\section{Research Hypothesis 1:}

The first research hypothesis stated that the nature of shyness of the secondary school students varies in terms of their medium of instruction. The result pertaining to difference between the two groups of students (male and female) and the result indicated that there exists a significant difference between the male and female students. The result indicated that gender influenced as influencing factor in case of predicting shyness. It is a social taboo specially in country like India that boys if he is shy then it is discouraged by his parents and others during the interaction. But shyness among the girls was rewarded and encouraged by society (Radke-Yarrow, Ritchers 


\section{Locus of Control and Teacher Student Interaction of the Adolescent Students within the Prison of Shyness}

\&Wilson, 1988). The result of the study also showed a similar pattern with the study of Engfer (1993) and Stevenson-Hinde(1989). They also conclude that shyness in girls is likely to be rewarded and accepted by parents, whereas shyness in boys is more likely to be discouraged. In one longitudinal study, however, parents rated their daughters as slightly more shy than of their sons at 18 and 30 months, but not subsequently at 50 months (Mathiesen and Tambs, 1999). Also girls are not more likely than boys to be nominated by their peers as shy/anxious or socially withdrawn in late childhood (Rubin, Chen \& Hymel, 1993). Yet in early adolescence some evidence indicates that girls tend to self report being shy more than boys (Crozier,1995)

Another area means medium of teaching plays not a significant role in predicting shyness. Though interaction between sex and medium of interaction produce a significant result but it cant be said that medium plays a significant role. The result of this finding also shows some similarity with the work of Chatterjee and Ray (2007).

\section{Research Hypothesis 2:}

The second hypothesis stated that irrespective of sex, the nature of the teacher student interaction of the students varies in terms of their different level of shyness (high and low). It was found from the result that a significant difference exists among the students in teacher student interaction due to different level of shyness and sex also. A similar pattern of results has been found in the school environment, as teachers tend to praise boys for outspoken behavior but praise girls restraining spontaneous conversation in the classroom (AAUW Educational Foundation, 1995).Asendorpf (1993) characterized shyness as reflecting two competing social motivations. Shy children often desire social interaction but this social approach motivation is inhibited by fear induced social avoidance (Coplan et.al., 1998). There is growing evidence to suggest a biological basis for early shyness and social inhibition during time of social interaction among the adolescents. Extremely shy and inhibited children are thought to possess a low threshold for physiological arousal, evidenced by a constellation of physiological characteristic that differentiate them from their uninhibited counterparts. (Marshall \& Stevenson-Hinde, 2001). During later childhood and into adolescence, shyness becomes increasingly associated with loneliness, depression, social anxiety, lower self worth and the use of positive coping strategies (Crozier,1995, Eisenberg, Fabes, Spheard, Murphy \&Guthire, 1998; Prior, Smart, Sanson \& Oberklaid,2000). Moreover shy children are extremely risk for the development of anxiety disorder and lack of social interaction in the later childhood and adolescence (Schwartz, Snidman, Kagan,1999)

A significant difference in teacher student interaction also comes due to sex. Several research studies also support this notion. Research has shown that girls have an overall higher quality of relationship with teachers (O’Connor \&McCartney,2006;Pianta \& Stuhlman, 2004). In turn research has shown that high level of closeness is also beneficial for girls on measures of social competence and social interaction. This means that for girls, not boys, higher level of closeness

in the relationship predicts school appropriate behavior and better social behavior such as being considerate of others (Ewing \&Taylor, 2009). Whereas girls experience more closeness in 


\section{Locus of Control and Teacher Student Interaction of the Adolescent Students within the Prison of Shyness}

teacher relationship which is an indicator of interaction with teachers. Teachers typically perceive relationship with boys to be less close and more conflictual. Indeed there is extensive support in the literature for the notion that teachers experience more conflict in relationship with boys (Baker,2006, Haughes et.al.,2001;Ladd et.al.,2008, Murray et.al.,2008 \& Pianta, 2001) and this conflict seems to particularly harm boys and their interaction with the teachers in classroom and outside the classroom. The increase in the amount of conflict in teacher-student relationship for boys has been linked to a decrease in school competence, an increase in hostile aggressive behavior (Ewing \& Taylor, 2009) and lower grades (DiLalla, Marcus \& Wright-Philips,2004).

\section{Research Hypothesis 3:}

The third research hypothesis was irrespective of sex, the nature of locus of control of the students varies in terms of their level of shyness. From the result it was found that a significant difference between the students locus of control comes due to level of shyness and sex. Previous researches in this field also support the result of the study. Bruch and Pearl (1995) found a strong relationship between shyness and locus of control. This result of the study also supports this notion. Hence research supports the result of that present study. It was also found from the research of Henderson and Zimbardo (1998) shy individuals self enhancement bias also play a reverse role.

A study on shy and non shy persons also indicated that both shy and non shy individuals are inclined to ascribe other hypothetical individuals' behavior to internal causes. But non shy individuals were inclined to ascribe their own behavior to external causes. This may like to be shy persons were more self conscious than the non shy individuals. As a result shy individuals ascribe their own behaviours to internal causes (Alm and Lindberg, 1999). In another study it was also found that shy individuals more frequently than non shy individuals stated that negative outcomes were caused by stable internal causes such as shyness or (lack of) intelligence. Also, non shy individuals than shy individuals stated maore frequently than shy individuals that positive outcomes were determined by stable internal causes, whereas shy individuals more frequently than non shy individuals stated that these outcomes were caused by unstable internal causes (Teglasi and Hoffman, 1982).

\section{Research Hypothesis 4:}

The fourth hypothesis stated intercorelation among all the variables. It was found that from the result, shyness was correlated with both teacher student interaction and locus of control. Positively. Several researches indicated that persons who were shy face a great deal of problem during their time of social interaction in social gatherings, school and workplace. So it was found from the researches that shyness and social interaction has a relationship with each other (Rosenbaum, Biederman, Hirshfield, Bolduc \& Chaloff, 1991). These researches also support the result of the present study. Shyness and locus of control also positively correlated with each other previous researches in this area also find the same thing (Alm \& Lindberg, 1999). 


\section{CONCLUSION}

There seems to be a relationship between shyness and teacher student interaction of the students. It was also found that shyness was positively correlated with teacher student interaction and locus of control of the students. Also it was found that shy and non shy students were differing significantly in both teacher student interaction and locus of control. Therefore it was said that shyness may also play an important role in predicting students different types of locus or how they interpret or analyze different event in their life. In summary, the finding of the study suggests that the quality of life for shy students was less than pleaseant. Shy students were sometimes socially different, anxious, lonely, rejected and insecure in social situations. They fail to exhibit a good interpersonal communication skill and tend to believe themselves to be deficient in social skills and interaction with others.

\section{REFERENCES}

Asendorpf, J. (1993). Abnormal shyness in children. Journal of Child Psychology and Psychiatry, 34, 1069-1081.

Alm, C. \& Lindberg, E.(1999), Attributions of shyness-resembling behaviors by shy and non-shy individuals. Personality and Individual Differences, 27, 575-585.

Baker, J,A. Contributions of teacher-child relationships to positive school adjustment during elementary school. Journal of School Psychology. 2006; 44:211-229

Bruch, M. A. (1989). Familial and developmental antecedents of social phobia: Issues and findings. Clinical Psychology Review, 9, 37-47.

Bruch, M. A. \& Pearl, L.(1995), Attribution style and symptoms of shyness in heterosexual interaction, cognitive therapy and research, 19 (1), 91-107

Buss, A. H. (1985). Two kinds of shyness. In R. Schwarzer (Ed.), Self-related cognitions in anxiety and motivation. Hillsdale, NJ: Erlbaum

Blanchard, A.L. \& Henle, C.A., (2008) Correlates of different forms of cyber loafing: The role of norms and external Locus of Control. Computers in Human Behavior, 24 (3), 1067-1084.

Brophy, J (1995) Working with Shy or Withdrawn Students. ERIC Digest. Ericdigests.org

Crozier, W. R. (1995). Shyness and self-esteem in middle childhood. British Journal Of Educational Psychology, 65, 85-95..

Crozier, W. R. (2002). Shyness and behavioural inhibition, British Psychological Society,15, pp.460-463.

Chatterjee, P. \& Ray, A. (2007), Assessment of shyness and personality attributes among secondary students in schools of Kolkata city, journal of Applied psychology, vol. 12 \& 13, pp. 32-39.

Cheek, J. M., Carpentieri, A. M., Smith, T. G., Rierdan, J., \& Koff, E. (1986). Adolescent shyness. In W. H. Jones, J. M. Cheek, \& S. R. Briggs (Eds.), A sourcebook on shyness: Research and treatment.New York: Plenum 


\section{Locus of Control and Teacher Student Interaction of the Adolescent Students within the Prison of Shyness}

Coplan, R. J et. al.. (1998). Exploring and assessing nonsocial play in the preschool: The development and validation of the Preschool Play Behavior Scale. Social Development, 7, $72-91$

DiLalla et al., 2004 • L. F. DiLalla, J. L. Marcus, and M. V. Wright-Phillips, Longitudinal effects of preschool behavioral styles on early adolescent school performance, Journal of School Psychology 42 (2004), pp. 385-401.

Eisenberg, N., Shepard, S.A., Fabes, R.A., Murphy, B.C, \& Guthrie, I.K. (1998). Shyness and children's emotionality, regulation, and coping: Contemporaneous, longitudinal, and across-context relations. Child Development, 69, 767-790.

Ewing, A. R., \& Taylor, A. R. (2009). The role ofchild gender and ethnicity in teacher-child relationship quality and children's behavioral adjustment in preschool. Early Childhood Research Quarterly, 24, 92-105.

Engfer, A. (1993). Antecedents and consequences of shyness in boys and girls: A 6-year longitudinal study. In K. H. Rubin \& J. B. Asendorpf (Eds.), Social withdrawal, inhibition, and shyness (pp. 49-79). Hillsdale, NJ: Erlbaum.

Fosterling, F. (1988), Attribution theory in clinical psychology, Chichester : Wiley

Gupta, A, \& Fisher, D. (2011), teacher-student interactions in a technology-supported science classroom environment in relation to selected learner outcomes: an indian study, Journal of Educational Studies, Trends \& Practices: Vol. 1 (1) May 2011

Honig, A. (1987). The Shy Child. young children 42(4): 54-64. EJ 358395.

Hair, M., Renaud, K.V., Ramsay, J. (2007) The Influence of Self-Esteem and Locus of Control on Perceived Email-Related Stress. Computers in Human Behavior. 23(6), 2791-2803.

Hughes JN, Cavell TA \& Prasad-Gaur A (2001). A Positive view of peer acceptance in aggressive youth risk for future peer acceptance. Journal of School Psychology. 2001;39: 239-252.

Harter, S. (1999). The construction of the self: A developmental perspective. New York: Guilford press.

Henderson, L. \& Zimbardo, P. (1998),: shyness, Encyclopedia of mental health, Academic press.

Henderson, L.,et.al. (2010). Shyness. Corsini Encyclopedia of Psychology. 1-3.

Kemple, Kristen M. (1995). Shyness and Self-Esteem in Early Childhood. journal of humanistic education and development 33(4): 173-82. EJ 509552.

Mathiesen K. S. \& Tambs K. (1999) The EAS Temperament Questionnaire - factor structure, age trends, reliability, and stability in a Norwegian sample. Journal of Child Psychology and Psychiatry 40, 431-9

Murray C, et. al..(2008) Child and teacher reports of teacher-student relationships: Concordance of perspectives and associations with school adjustment in urban kindergarten classrooms. Journal of Applied Developmental Psychology. 2008:29:49-61 
Marshall, P. J., \& Stevenson-Hinde, J. (2001). Behavioral inhibition: Physiological correlates. In W. R. Crozier \& L. E. Alden (Eds.), International handbook of social anxiety (pp. 53-66). New York: Wiley.

O’Connor and McCartney, 2006 • E. O’Connor and K. McCartney, Testing associations between young children's relationships with mothers and teachers, Journal of Educational Psychology 98 (2006), pp. 87-98.

Prior, M, Smart, D., Sanson, A, \& Oberklaid, F. (2000). Does shy-inhibited temperament in childhood lead to anxiety problems in adolescence? Journal of the American Academy of Child and Adolescent Psychiatry 39, 461-468

Rotter, J. B. (1966). Generalized expectancies for internal versus external control of reinforcement. Psychological Monographs, 80, 1-28.

Rosenbaum, J. F., Biederman, J., Hirshfeld, D. R., Bolduc, E. A., \& Chaloff, J. (1991) Behavioral inhibition in children: A possible precursor to panic disorder or social phobia.Journal of Clinical Psychiatry, 52, 5-9.

Rubin, K.H., Chen, X., \& Hymel, S. (1993). Socioemotional characteristics of withdrawn and aggressive children. Merrill-Palmer Quarterly, 39, 518-534.

Radke-Yarrow, M., Richters, J. \& Wilson,W,E. (1988). Child development in a network of relationships. In R.A.Hinde \& J. Stevenson-Hinde (Eds) Relationships within families: Mutual influences (pp. 48-67). Oxford: Clarendon Press.

Saft and Pianta, 2001 • E. W. Saft and R. C. Pianta, Teachers' perceptions of their relationships with students: Effects of child age, gender, and ethnicity of teachers and children, School Psychology Quarterly 16 (2001), pp. 125-141.

Schwartz, C. E., Snidman, N., \& Kagan, J. (1999). Adolescent social anxiety as an outcome of inhibited temperament in childhood. Journal of the American Academy of Child \& Adolescent Psychiatry, 38, 1008-1015.

Stuhlman and Pianta, 2002 • M. W. Stuhlman and R. C. Pianta, Teachers' narratives about their relationships with children: Associations with behavior in classrooms, School Psychology Review 31 (2002), p. 148.

Stevenson-Hinde, J. (1989). Behavioral inhibition: Issues of context. In J. S. Reznick (Ed.), Perspectives on behavioral inhibition (pp. 125-138). Chicago: University of Chicago

Teglasi, H., \& Hoffman, M. A. (1982). Causal attributions of shy subjects. Journal of Research in Personality, 16, 376-385.

Thompson, C., and L. Rudolph. (1992). COUNSELING CHILDREN (3rd ed.). Pacific Grove, CA: Brooks/Cole.

Weiner, B. (1986) An attributional theory of motivation and emotion, New York, SpringerVerlag.

Zimbardo, P. G. (1977). Shyness: What it is, what to do about it. Reading, MA: AddisonWesley. 
Locus of Control and Teacher Student Interaction of the Adolescent Students within the Prison of Shyness

Tables

Table -1: Mean \& SD Value Of Shyness \&Its Components

\begin{tabular}{|l|l|l|l|l|l|}
\hline \multirow{2}{*}{$\begin{array}{l}\text { Components } \\
\text { Of Shyness }\end{array}$} & & \multicolumn{2}{|c|}{ English } & \multicolumn{2}{c|}{ Bengali } \\
\cline { 2 - 6 } & & Male & Female & Male & Female \\
\hline \multirow{3}{*}{ Overall } & Mean & 69.80 & 68.93 & 60.86 & 73.60 \\
\cline { 2 - 6 } & Sd & 16.35 & 14.49 & 10.08 & 8.23 \\
\hline \multirow{3}{*}{ Physiological } & Mean & 22.96 & 22.65 & 19.06 & 23.40 \\
\cline { 2 - 6 } & Sd & 6.99 & 6.71 & 5.08 & 3.97 \\
\cline { 2 - 6 } & Mean & 9.33 & 9.66 & 10.16 & 10.56 \\
\hline Cognitive & Mean & 2.82 & 2.32 & 2.29 & 2.52 \\
\cline { 2 - 6 } & Sd & 22.90 & 23.80 & 18.53 & 21.70 \\
\hline \multirow{3}{*}{ Affective } & Mean & 14.63 & 14.63 & 13.10 & 17.76 \\
\cline { 2 - 6 } & Sd & 4.45 & 4.45 & 3.56 & 3.27 \\
\hline
\end{tabular}

Table 2: F-Ratio Value Of The Shyness \& Its Different Components

\begin{tabular}{|l|l|l|}
\hline Components Of Shyness & Sources Of Variation & F-Ratio \\
\hline \multirow{5}{*}{ Overall } & Sex & $6.98^{*}$ \\
\cline { 2 - 3 } & Medium & 1.02 \\
\cline { 2 - 3 } & Interaction & $8.94^{*}$ \\
\hline \multirow{5}{*}{ Behavioural } & Sex & $4.69^{*}$ \\
\cline { 2 - 3 } & Medium & 1.30 \\
\cline { 2 - 3 } & Interaction & $3.89^{*}$ \\
\hline \multirow{5}{*}{ Affective } & Sex & $4.67^{*}$ \\
\cline { 2 - 3 } & Medium & 3.38 \\
\cline { 2 - 3 } & Interaction & $3.75^{*}$ \\
\hline \multirow{5}{*}{ Physiological } & Sex & 3.40 \\
\cline { 2 - 3 } & Medium & $10.96^{*}$ \\
\cline { 2 - 3 } & Interaction & 2.64 \\
\hline & Sex & $6.80^{*}$ \\
\cline { 2 - 3 } & Medium & 0.25 \\
\cline { 2 - 3 } & Interaction & $14.45^{*}$ \\
\hline
\end{tabular}

*significant at 0.05level 
Locus of Control and Teacher Student Interaction of the Adolescent Students within the Prison of Shyness

Table 3: Mean, Mean Difference And F-Ratio Values For Teacher Student Interaction And Locus Of Control According To Sex And Different Level Of Shyness.

\begin{tabular}{|c|c|c|c|c|c|}
\hline \multirow[t]{2}{*}{ Components } & \multicolumn{2}{|c|}{$\begin{array}{l}\text { Mean Values \& Mean Differences Of } \\
\text { Scores Of Students }\end{array}$} & \multicolumn{3}{|c|}{$\begin{array}{l}\text { The Values Of F-Ratio Sources For } \\
\text { Variation Due To }\end{array}$} \\
\hline & $\begin{array}{l}\text { Sex Difference } \\
\text { (Male \& Female) }\end{array}$ & $\begin{array}{l}\text { Different Level } \\
\text { Of Shyness (High } \\
\text { \& Low) }\end{array}$ & $\begin{array}{l}\text { Sex } \\
\text { Difference }\end{array}$ & $\begin{array}{l}\text { Level Of } \\
\text { Shyness }\end{array}$ & \begin{tabular}{l}
\multicolumn{2}{l}{ Interaction } \\
\multicolumn{2}{l}{ Between } \\
Sex And \\
Level Of \\
Shyness
\end{tabular} \\
\hline $\begin{array}{l}\text { Teacher } \\
\text { Student } \\
\text { Interaction }\end{array}$ & $\begin{array}{l}\text { Male=10.05 } \\
\text { Female }=11.6556 \\
\text { Difference }=1.6056\end{array}$ & $\begin{array}{l}\text { High }=10.9444 \\
\text { Low }=8.9231 \\
\text { Difference }=2.0213\end{array}$ & $4.449 *$ & $9.584 * *$ & 5.563* \\
\hline $\begin{array}{l}\text { Locus Of } \\
\text { Control }\end{array}$ & $\begin{array}{l}\text { Male }=8.922 \\
\text { Female }=10.1833 \\
\text { Difference }=1.2611\end{array}$ & $\begin{array}{l}\text { High }=9.9167 \\
\text { Low }=8.9744 \\
\text { Difference }=.9423\end{array}$ & $6.348 *$ & 3.436* & 1.161 \\
\hline
\end{tabular}

Table 4: Correlation Values among Shyness, Teacher Student Interaction And Locus Of Control.

\begin{tabular}{|l|l|l|l|}
\hline Components & $\begin{array}{l}\text { Teacher Student } \\
\text { Interaction }\end{array}$ & Shyness & Locus of Control \\
\hline $\begin{array}{l}\text { Teacher Student } \\
\text { Interaction }\end{array}$ & 1 & & \\
\hline Shyness & $.194^{*}$ & 1 & 1 \\
\hline Locus of Control & .016 & $.325^{* *}$ & 1 \\
\hline
\end{tabular}

$*_{r}$ value significant at 0.05 level $\quad * *$ r value significant at 0.01 level 